\title{
A CASE OF RUPTURE OF THE INTRATHORACIC PORTION OF THE TRACHEA
}

\author{
BY \\ B. J. BICKFORD AND PHILIP W. ROBERTSON \\ From the Liverpool Thoracic Surgical Centre and the Medical Branch, Royal Air Force
}

(RECEIVED FOR PUBLICATION MARCH 24, 1958)

Rupture of the trachea or a large bronchus is a recognized though rare result of severe crush injuries of the chest, especially in children and young adults. Because of the rarity of reports of successful emergency surgical treatment, we present a further example of such an injury.

\section{CASE REPORT}

On May 13, 1956, in Western Germany, a road accident occurred in which a private car came into collision with the trailer of a lorry. The car was extensively damaged and the driver, a British soldier, was flung violently on to the steering wheel. Though dazed, he was not unconscious and was able to extricate himself from the wreckage.

When admitted to hospital he was complaining of pain in the chest and he had coughed up a little blood. He had minor abrasions of the face and elsewhere; otherwise the chief finding was extensive bruising over the right upper chest anteriorly. Within a few hours swelling of the face and neck developed, with cyanosis of the extremities. The earliest chest

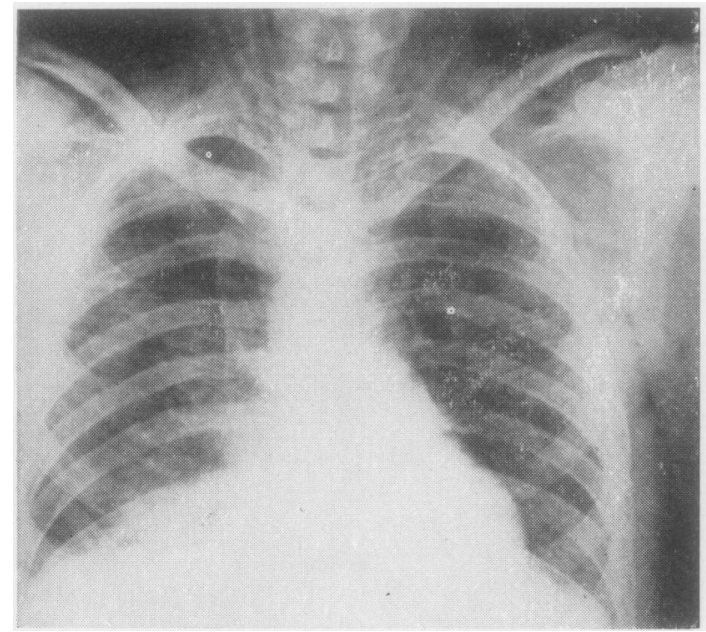

Fig. 1.-Postero-anterior radiograph of the chest on admission showing gross mediastinal and subcutaneous emphysema. radiograph (Fig. 1) showed no damage to the thoracic cage and no pneumothorax, but emphysema of the chest wall and mediastinum was obvious. Over the next three days the subcutaneous emphysema increased progressively and alarmingly. He was first seen by one of us (P. W. R.) on May 17, four days after the accident. At this time the emphysema was widespread. The eyes were completely closed and could not be opened, and the lips were forced apart and could not be closed. The whole body, even to the finger-tips and toes, was tensely inflated and tympanitic to percussion. The patient, who weighed 16 st. and was $6 \mathrm{ft} .4$ in. tall (Fig. 2), resembled the man in the well-known motor-tyre advertisement.

Bronchoscopy (Squadron-Leader D. G. Jones) was difficult, because the tension in the tissues of face and neck made manipulation almost impossible, but a mucosal laceration in the lower trachea was seen, though its exact extent could not be determined.

A diagnosis of rupture of the lower end of the trachea was made, and it was clear that only early surgical repair could save the patient's life. He was transferred to an R.A.F. hospital, and with the

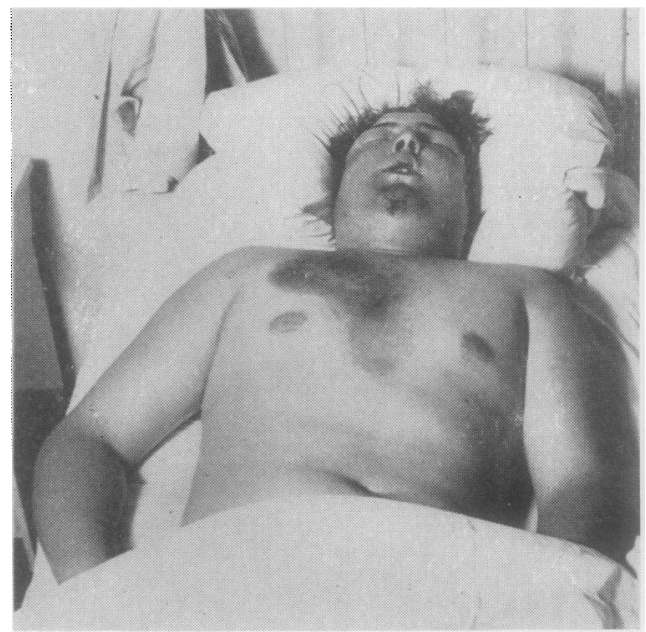

FIG. 2.-Appearance of the patient on admission showing gross subcutaneous emphysema. 
co-operation of the Royal Air Force authorities the surgical member of the team (B. J. B.) was flown within a few hours from England to Germany.

A further chest film showed a pneumothorax on the right side which had developed during the previous few hours, so a needle attached to an underwater seal was placed in the right pleural space; the air was under considerable tension. Another needle inserted into the scrotum relieved the tension in the perineal region so that the patient could then empty his bladder. These procedures also enabled him to open his eyes for a few moments, though they soon closed again.

Induction of anaesthesia, with thiopentone (350 mg.) and succinylcholine chloride (40 mg.), began about seven hours after the patient was first seen in consultation by P. W. R., and was not an easy task for Squadron-Leader A. J. Merrifield, who administered the anaesthetic. It was difficult to inflate the lungs, as the thickness and tension of the chest wall called for considerable compressive force on the rubber reservoir bag in order to maintain oxygenation. As had been foreseen, this positive pressure forced more air though the tracheal tear, and made it essential to proceed to thoracotomy without delay. It did seem necessary to inspect the region of the injury again through a bronchoscope in order to make sure of the exact site of injury. A cuffed tube was then passed blindly into the left main bronchus and it was found that it was possible to maintain reasonable oxygenation with inflation of the left lung alone. A right postero-lateral thoracotomy was performed with the patient in the lateral position, and the pleural cavity entered through the fifth intercostal space. After this, inflation of the left lung was easier, but for some time during the operation oxygenation was probably inadequate. All the tissues of the chest wall were greatly distended with air, as also were the subpleural tissues on the chest wall and mediastinum. A small tear in the pleura could be seen just below the azygos vein, and after division of this structure it was found that there was a longitudinal rent, about $4 \mathrm{~cm}$. in length, in the right side of the lower part of the trachea extending into the right main bronchus. The injury was at the junction of the cartilaginous and membranous portions of the tracheal wall (Fig. 3). The laceration was easily repaired with a number of fine stainless-steel wire sutures inserted on atraumatic needles. After withdrawal of the endotracheal tube for a suitable distance, the right lung inflated well, and there was a corresponding improvement in the patient's general condition. The repair was air-tight, and it was not necessary to reinforce the suture line. The chest was closed with intercostal drainage.

When the endotracheal tube was removed the patient's own respiratory efforts were not enough to maintain satisfactory oxygenation, so that re-intubation and further manual inflation were necessary. This sequence was repeated three times, and considerable anxiety was felt because spontaneous respiration was not resumed until 30 minutes after the end of the operation in spite of the administration of prostigmine and atropine. Assisted respiration was continued for some time after spontaneous breathing had returned. The patient was returned to the ward about four and a half hours after the original induction of the anaesthetic.

The post-operative period was stormy. For three or four days the patient's temperature went up to 103 or $104^{\circ} \mathrm{F}$. with a pulse rate varying between 140 and 160 and a respiratory rate on occasion up to 50 per minute. Fortunately the patient was of a robust constitution, both physically and mentally; it is doubtful if a less hardy patient would have survived. Every effort was made to reduce the strain on his physical reserve and a modified cooling technique was used to reduce the fever and the general metabolic load in the post-operative period. $\mathrm{He}$ was given largactil, pethidine, and phenergan, together with some surface cooling which reduced the body temperature to a more reasonable level. On account of some difficulty with secretions in the bronchial tree, oxygen and alevaire were administered through an atomizer and neo-epinine was given to reduce

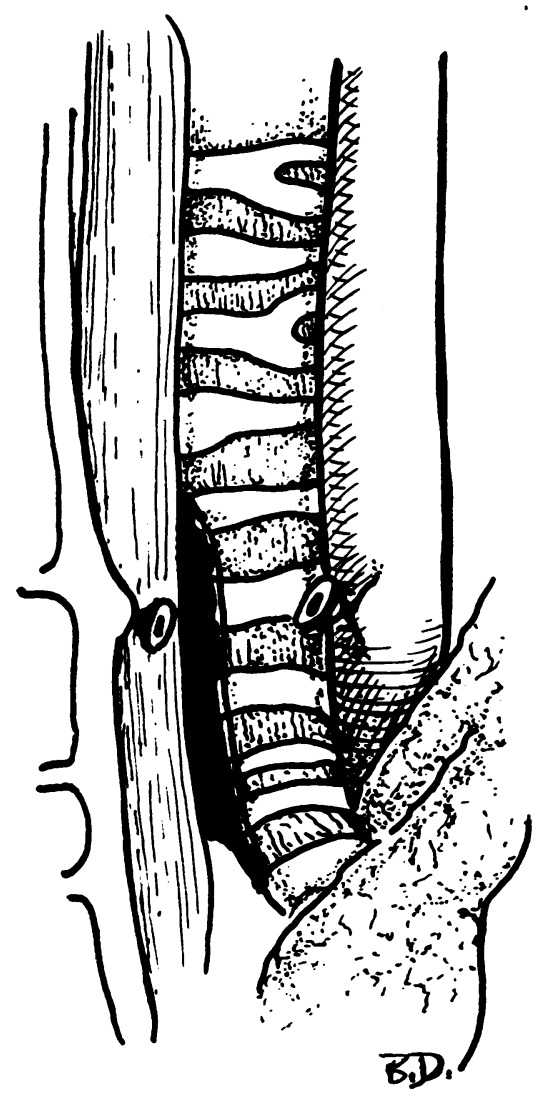

FIG. 3.-Drawing of operative findings. The azygos vein has been divided and the laceration of the trachea and the upper part of the right main bronchus is seen from the right side. 


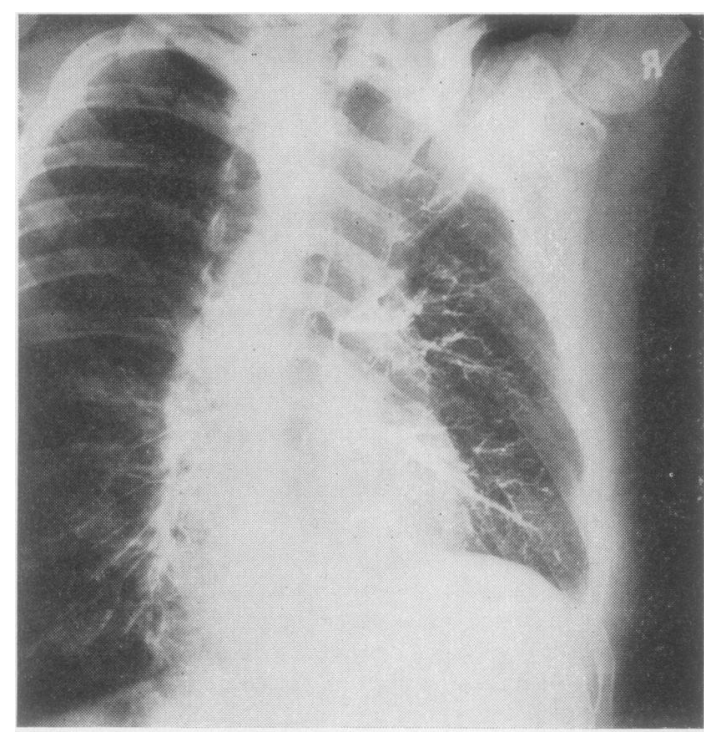

FIG. 4.-Post-operative bronchogram showing slight distortion in the region of the right upper lobe bronchus, but no significant narrowing of the lumen.

bronchial spasm. Improvement began after the fifth post-operative day, and was uninterrupted. Bronchoscopy about a month after the operation showed a little débris still present at the site of the tear. This was removed, and a slight ridge could be felt along the suture line, but there was no bronchostenosis. A bronchogram was satisfactory (Fig. 4). The patient resumed his duties as a soldier in August, 1956 (five months after injury). He has remained in good health, and when seen in January, 1958, his only complaint was occasional wheeziness on exertion. A chest. radiograph was normal (Fig. 5).

\section{Discussion}

To read the record of instances of rupture of the trachea or main bronchi reported in the literature is to read a summary of the influence of thoracic surgery on chest injuries. The 21 cases recorded before 1928, and summarized by Kinsella and Johnsrud (1947), were all fatal results of a severe injury discovered at necropsy, death having occurred either immediately or within a few days. Krinitzki (1927) reported a patient who survived for seven years with a stricture of the right main bronchus, only to die of tuberculosis in the opposite lung. After this a number of recoveries were reported, though almost invariably with a bronchostenosis and atelectasis. In the paper quoted, Kinsella and Johnsrud collected 38 cases of ruptured bronchus from the literature and added two of their own. One of these patients was treated by pneumon-

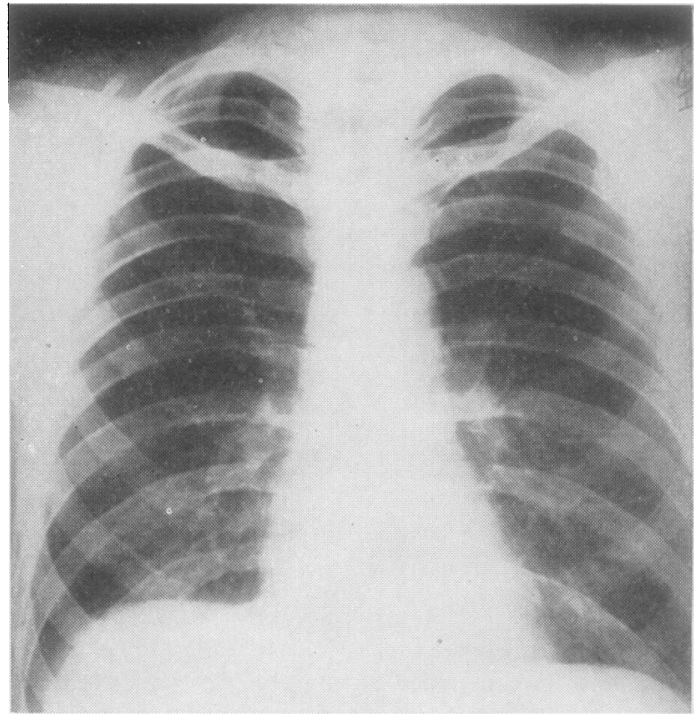

FiG. 5.-Post-operative radiograph of the chest.

ectomy two and a half years after the injury. This was the first recorded case of such an intervention, and the authors foresaw that direct $\frac{}{2}$ surgical repair might become feasible in the future. Four years later Scannell (1951) reported the first instance of immediate repair of a ruptured bronchus and several subsequent successes have been recorded. Griffith (1949) was the first to excise a traumatic stricture of the bronchus and this again has been since reported on a number of occasions. If gross infection has not taken place, re-expansion of the lung can follow successful repair years after an injury which has caused a complete bronchostenosis. The longest reported time between the accident and the successful excision of a stricture with re-expansion of the lung appears to be 15 years. This is the case mentioned by Paulson and Shaw (1955) as having been treated by Samson and Evans.

Thompson and Eaton reviewed the literature up to 1955 , and found 20 additional examples of rupture of the trachea or main bronchi ; five had been treated by pneumonectomy and nine by repair of the injured air passage. They added two patients of their own, one treated by immediate repair of a tear in the trachea (together with a right upper lobectomy), and the other by a successful repair, two months after the injury, of a complete rupture of the left main bronchus. We ourselves have reviewed the literature up to the present time, and have found 20 further 
examples. The clinical features were not different from those reported in earlier papers. Only five of these 20 patients were operated on within seven days of the injury and in four of these repair was successful. Dark and Jewsbury (1955) removed the avulsed right upper lobe and repaired a slit $2 \mathrm{~cm}$. long in the lower end of the trachea ; Ellis, Andersen, and Hayles (1955) were able to repair a complete rupture of the right main bronchus above the upper lobe ; Richards and Cohn (1955) sutured a lacerated right main bronchus and Wenzl (1956) repaired two lacerations in the right side of the lower part of the trachea. In one of the three patients reported by Richards and Cohn it was only possible to do a permanent tracheostomy. Of 10 patients submitted to surgery within six months of injury, repair was still feasible in six: Eckman, Rosenberg, and Gall (1956) repaired a right main bronchus ruptured and stenosed above the upper lobe orifice using a dermal graft reinforced by wire stiffening; Richards and Cohn (1955) resected and re-sutured a ruptured right main bronchus; Sauvage (1954) was able to re-implant a right main bronchus into the trachea three months after injury ; and Sheehy and Hopeman (1955) resected a portion of the right main bronchus seven weeks after injury. Bates and Beard (1956) report two instances in which. a successful repair was carried out three months after injury; in one, the left main bronchus was completely torn across, and in the other the right main bronchus had been replaced by a fibrous cord for $1 \frac{1}{2} \mathrm{~cm}$. immediately distal to the carina. Both patients recovered.

In four others it was only possible to do a resection. Dalgleish, Hazen, and Kinnear (1954) performed a right pneumonectomy on a 6-yearold boy two months after injury ; Perásolo (1956) had to do a left pneumonectomy three months after injury, and Sale (1954) reports a right middle and lower lobectomy five months after injury. Bates and Beard (1956) reported a case in which a left pneumonectomy had to be performed 15 days after the injury because of the comminution of the wall of the left main bronchus at the site of the injury. Recovery was uneventful. Two patients were operated on later; for one a left pneumonectomy was performed five years afterwards (Sale, 1954) and for the other a thoracoplasty was carried out for a late chronic empyema (Hasche, 1953). One patient, reported by Fowler (1955), died without surgery.

To summarize the literature; 82 cases of traumatic rupture of the trachea or main bronchi within the chest have been recorded, but only 21 of these have been subjected to reparative surgery, all with recovery of the patient. Eleven further patients have been treated by lung resection alone, usually at a considerable time after the accident. It is evident that a rupture of the trachea or main bronchi should be repaired surgically as soon after injury as possible, and that if this is done the expectation of recovery is good. Repair by simple suture appears to be the most satisfactory method, although reinforcement by muscle graft or tantalum mesh may be advisable in some instances. Later repairs are hazardous because the bronchial stricture developing with inflammatory fibrosis after injury may make resection of the stricture and re-anastomosis difficult. Complete re-expansion of the lung is likely if infection has not taken place distal to the injury.

Rupture of a major air passage should be suspected in closed chest injuries when there is a tension pneumothorax with a large escape of air after drainage of the pleural cavity, or when there is gross and progressive mediastinal and subcutaneous emphysema. Rupture of the main bronchi appears more likely to produce a pneumothorax than rupture of the trachea which may, as in the present instance and as in the case reported by Wenzl (1956), result in extensive tissue emphysema without there being a pneumothorax.

The injury is generally in a young person who has an intact thoracic cage. The mechanism of the injury has been the subject of some speculation and remains obscure. The most likely cause seems to be a violent deceleration of the body as a result of an impact in which the weight of the lungs is thrown forwards. Such a force might tear across a main bronchus or provide a shearing strain which could partially or completely separate the right upper lobe from the right main bronchus or a main bronchus from the trachea. The left main bronchus is somewhat protected from such violence as its upper part is sheltered behind the arch of the aorta, and this may account for the greater incidence of these injuries on the right side.

The idea that the lungs are thrown forward violently on their hilar attachment receives support from the observations that the majority of reported cases have been in children and young adults, and that fractured ribs are an infrequent accompaniment of the injury. A depressed fracture of the "stove-in" variety would no doubt provide a certain cushioning effect of the blow on the lung hilum.

This may not be the whole story, and it is difficult to account in this manner for the ruptures of 
the trachea observed, for example, by Dark and Jewsbury (1955) and by Wenzl (1956). In our own example, the injury was predominantly in the lowest part of the trachea. Here is a possible place for the suggestion put forward by Schönberg (1912) that an external blow added to forced expiration against a closed glottis in a moment of fright might raise the pressure in the main air passages to bursting point. The matter is, however, academic and the important point to remember is that tension-pneumothorax or gross subcutaneous emphysema after a chest injury may be due to a ruptured main air passage. Once the diagnosis is made, early thoracotomy offers the best prospect of recovery for the patient.

\section{Summary}

The literature of rupture of the intrathoracic trachea and main bronchi is reviewed.

Eighty-two cases have been collected from the literature, of which 32 have been treated by major surgery, 11 by resection and 21 by repair.

A further example of rupture of the intrathoracic trachea with successful early surgical repair is recorded.

We wish to place on record our gratitude to Squadron-Leader D. G. Jones, who performed the original bronchoscopy and confirmed the diagnosis, and to Squadron-Leader A. J. Merrifield, whose skilful anaesthesia made a successful outcome of the operation possible. We also wish to thank the Royal Air Force authorities for making speedy surgical aid possible through their transport facilities, the Director General of Medical Services, Royal Air Force, for permission to publish this report, Dr. Robert Coope for his help in preparation of this report, and Miss Barbara Duckworth for the illustration.

\section{REFERENCES}

Bates, M., and Beard, H. J. (1956). Thorax, 11, 312.

Dalgleish, H. D., Hazen, G. M. T., and Kinnear, W. S. (1954) Canad. med. Ass. J., 70, 45.

Dark, J., and Jewsbury, P. (1955). Thorax, $10,62$.

Eckman, W. G., Jr., Rose ibe:z, B. N., and Gall, E. B. (1956) Ann. Surg., 143, 98.

Ellis, F. H., Jr., Andersen, H. A., and Hayles, A. B. (1955). Proc. Mayo Clin., 30, 268.

Fowler, A. W. (1955). Brit. med. J., 1, 85.

Griffith, J. Ll. (1949). Thorax, 4, 105.

Hasche, E. (1953). Thoraxchirurgie, 1, 357.

Kinsella, T. J., and Johnsrud, L. W. (1947). J. thorac. Surg., 16, 571

Krinitzki, S. I. (1927). Virchows Arch. path. Anat., 266, 815.

Paulson, D. L., and Shaw, R. R. (1955). J. thorac. Surg., 29, 238.

Perásalo, O. (1956). Ann. Chirg. Gynaec. Fenn., 45, 92.

Richards, V., and Cohn, R. B. (1955). Amer. J. Surg., 90, 253.

Sale, T. A. (1954). Brit. J. Surg., 41, 625.

Sauvage, R. (1954). Mém. Acad. Chir. (Paris), 80, 187.

Scannell, J. G. (1951). Ann. Surg., 133, 127.

Schönberg, S. (1912). Berl. klin. Wschr., 49, 2218.

Sheehy, J. L., and Hopenan, A. R. (1955). Laryngoscope (St. Louis), 65, 973 .

Thompson, J. V., and Eaton, E. R. (1955). J. thorac. Surg., 29, 260.

Wenzl, M. (1956). Arch. Klin. Chir., 284, 186. 